\title{
Biosynthesis and Characterization of Zinc Sulphide Nanoparticles Using Leaf Extracts of Tridaxprocumbens
}

\author{
M.SATHISHKUMAR ${ }^{1,2 *}$, DR.M. SAROJA ${ }^{1}$, DR. M. VENKATACHALAM ${ }^{1}$, \\ G.PARTHASARATHY ${ }^{1}$, and A.T.RAJAMANICKAM ${ }^{2}$ \\ ${ }^{1}$ Thin Film center, Department of Electronics, Erode Arts and Science College, \\ Erode, -638009 , Tamilnadu. \\ ${ }^{2}$ Department of electronics and communication systems, Nehru Arts and Science College, \\ Coimbatore, 641105, Tamilnadu. \\ *Corresponding author E-mail: mskeasc@gmail.com \\ http://dx.doi.org/10.13005/ojc/330240 \\ (Received: March 06, 2017; Accepted: March 09, 2017)

\begin{abstract}
In this paper, we discussed biosynthesized and characterization of zinc sulphide nanoparticles using tridaxprocumbens leaf extract by green synthesis method. This study focuses on the production of ZnS nanoparticles using tridaxprocumbens plant of methanol leaf extracts and analysis the antimicrobial activity. The formation of zinc sulphidenanoparticleswas characterized by using numerous analytical techniques such asScanning electron microscopy(SEM), Fourier transform infrared spectroscopy(FT-IR), X-ray powder diffraction (XRD) and UV-Visible spectroscopy (UV-Vis). The results showed that the leaf extract for the synthesis zinc sulphide nanoparticles to have the ability to inhibit the growth of various pathogenic microorganisms. The synthesized zinc sulphide nanoparticles can be used for various applications due to its ecofriendly,non-toxic and compatibility for pharmaceutical and other applications.
\end{abstract}

Keywords: Zinc suplhidenanoparticles, Tridaxprocumbens, Antimicrobial Activity, Scanning electron microscopy(SEM) and X-ray powder diffraction (XRD).

\section{INTRODUCTION}

From last decades, nanoparticles have been received too much attention due to its unique properties like high surface area, magnetic, thermal, mechanical, electronic and enhanced catalytic properties. The nanotechnology has beenremarkable development in the synthetic methodologies have been developed to various nanoparticles of shape, size, dimensions and so on ${ }^{1-2}$. For instance, various types of nanoparticles (NPs)are available such as metal $\mathrm{NP}^{3}$, carbon based nanomaterials ${ }^{4-7}$, and polymers ${ }^{8}$, mostcommonly nanoparticles are synthesis through chemical methods ${ }^{9}$, sol-gel processing ${ }^{10}$, co-precipitation, and electro deposition method $^{11}$. Zinc sulphide has been found highly 
attractive because of its remarkable application potential in solar cells, piezoelectric devices, UV-vis absorbers, pharmaceutical and cosmetic industries ${ }^{12}$. Potentially, Zinc sulphide removed all the dyes and water pollutants from textile effluent under UV light have been proved ${ }^{13-15}$. Zinc sulphide nanoparticles were large particle size in bulk materials, morphology and characteristics of the particles can be derived due to their new properties ${ }^{16}$. The amount of the atoms and size approaches nanoscale materials become memorable of their properties ${ }^{17}$. In pharmaceutical applicationsbiosynthesis of zinc sulphidenanoparticles using green chemistry, amethodis very useful and ecofriendly environmental method ${ }^{18}$. Although different biological based synthetic method is known for zinc sulphide are sought by researchers. Biosynthesis of zinc sulphide nanoparticles hasmany advantagesin pharmaceuticals applications because of use nontoxic materials ${ }^{19}$. Plants become the desirable and superior option for the safe, Nontoxic method of nanoparticles synthesis because the natural capping agents are readily taken from the plants ${ }^{20}$. Tridaxprocumbens is belonging to family Asteraceae. It's grown on waste lands and hill stations normally, the leaves and flowers are commonly toothed and arrowhead shaped, yellow colored flowers, Tridaxprocumbens plant has more herbal properties in pharmaceuticals ${ }^{21-22}$. Coat buttons is a common name of Tridaxprocumbens in English because of its flower appearance. In India its widely used ayurvedic medicine extensively like wound healing, liver disorders. Especially leaves are used skin infection ${ }^{23}$.

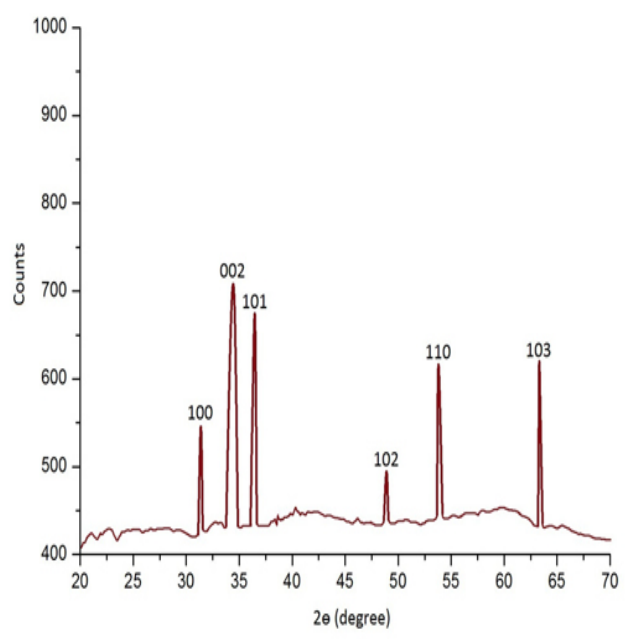

Fig. 1: XRD analysis of ZnSnanoprticles using leaf extract of tridaxprocumbens
Antiseptic, Parasiticidal, Insecticidal infections flowers and leaves also used ${ }^{24-26}$. Tridaxprocumbens full plants show various antibacterial and fungal activities against many microorganisms and various pharmacological activities ${ }^{27-32}$.

\section{Plant Extraction}

Tridaxprocumbens plant fresh leaveswere collected locally around thewaste land of idappadi, Salem. Collected leafs washed in DI water and paced shadow dried, coarsely powdered using agrinder. $250 \mathrm{ml}$ of methanol solvent, $25 \mathrm{~g}$ of coarse leaves powder to extracts by using soxhlet apparatus and stored extracts used further investigations.

\section{Alkaloids detection}

The hydrochloric acid used to test a presence of alkaloids, Tridaxprocumbens leaf extracts were dissolved in $\mathrm{HCL}$ and the extract was filtered. The presence of alkaloids to expedite yellow cream formation were filtrated extracts with Mayer's reagent and thepresence of alkaloids to precipitate brown or reddish brown colour formation were filtrates with Wagner's reagent.

\section{Flavonoids detection}

The presence of flavonoids to expedites yellow colour formation were asolution of lead acetate treat with drops of extracts and $\mathrm{H} 2 \mathrm{SO} 4$ were treating with leaf extract, orange colour formation to thepresence of flavonoids.

\section{Steroids detection}

Presences of steroids were leaf extract added $1 \mathrm{ml}$ of acetic anhydride with $\mathrm{H} 2 \mathrm{SO} 4$ expedites blue or green from violet colour.

\section{Terpenoids detection}

In salkowski's test presence of terpenoids, indicate reddish brown were leaf extract was mixed chloroform with $\mathrm{H}_{2} \mathrm{SO}_{4}$

\section{Athraquinones detection}

In borntrager's test presence of anthraquinonesexpeditespinkcolour, were $\mathrm{NH} 3$ drops was adding cool

Filtered with $\mathrm{CHCl} 3$ and before filtering extract was boiled $\mathrm{HCL}$ using awater bath in few minutes. 


\section{Phenols detection}

In Ferric chlorideand lead acetate test presence of phenol indicates bluish black colour formation were leaf extracts mixing with ferric chloride drop by drops,yellowcolour expedites were solution of lead acetate was adding in the extract

\section{Saponins and Tannins detection}

The presence of saponinswas extract shaken with DI water itindicate a frothing formation when ferric chloride added to filtrate of mixing heated water bath with extract to theformation of dark green colour indicate of tannins.

\section{Carbohydrates, Oil and Resins detection}

DI water was dissolved in extract and filtered carbohydrate presence was tested using filtrate. Were the test solution was applied on the filter paper its form a transparent appearance to indicate thepresence of oil and resins.

\section{Alkaloids estimation}

Harborne(1973) method to use determined of alkaloid, $200 \mathrm{ml}$ acetic acid was taken in $250 \mathrm{ml}$ of thebeaker and 4 to $5 \mathrm{~g}$ extract were added together and the beaker allowed to stand more then $4 \mathrm{~h}$ after that extract was filtered and treated to awater bath with original volume. Ammonium hydroxide was added drop by drop of the extract until it was complete. Once extracts were washed with dilute ammonium hydroxide solution it's filtered and weighed.

\section{Flavonoids estimation}

The filter paper was use to dry and weighed of flavonoids, In $250 \mathrm{ml}$ beaker uses to mixing $100 \mathrm{ml}$ of methanol and $10 \mathrm{~g}$ of leaf extract at room temperature.

\section{Steroids estimation}

$2 \mathrm{ml}$ of sulphuric acid, $2 \mathrm{ml}$ of iron chloride was added and $5 \mathrm{ml}$ of potassium hexacynoferrate solution were mixed with $10 \mathrm{ml}$ of tridaxprocumbens leaf extract, followed mixing were treated heating water bath at $20^{\circ} \mathrm{C}$ to $70^{\circ} \mathrm{C}$ in 30 minutes, then the mixed solution dissolved in DI water.

\section{Saponin determination}

The saponin content calculate using the methanol, $10 \mathrm{ml}$ methanol were treated with $10 \mathrm{ml}$ tridaxprocumbens plant extract it was dispersed and solution was using continuous stirring 4 hours at $55^{\circ} \mathrm{C}$ With heated hot water, after complete stirring solution was filtered and again $200 \mathrm{ml}$ methanol added. In that solution was heated till it reduce $90 \mathrm{ml}$ using heat water bath, from the $90 \mathrm{ml}$ solution $20 \mathrm{ml}$ of diethyl added and shacked with separate funnel and purification process was taken. In that purified solution was adding with $10 \mathrm{ml}$ of sodium chloride and remaining was treated water bathing and dried with help of oven.

\section{Apparatus and synthesis}

The surface morphology and EDX of the composite were studied by Hitachi S-4500 scanning electron microscope (SEM). Fourier transform infrared spectroscopy (FT-IR) was measurements were carried out by using JASCO FT/1 IR-6600 instrument. XRD pattern were analyzed by X-ray diffractometer (XPERT-PRO).

\section{Biosynthesis of zinc sulphide nanoparticles}

Tridaxprocumbens used to synthesis zinc sulphide nanoparticles were $14.4 \mathrm{~g}$ of zinc sulphate was added $100 \mathrm{ml}$ DI water, one millimole aqueous solution of zinc sulphate $\left(\mathrm{ZnSO}_{4}\right)$ was prepared, $20 \mathrm{ml}$ of methanol leaf extract were added drop by drop in $80 \mathrm{ml}(1 \mathrm{mM})$ of zinc sulphate aqueous solution which was kept continuous stirring for 2 hours at room temperature, result was indicate the formation of zinc sulphidenanocolloid, then the final solutiondried at $60^{\circ} \mathrm{C}$ for 5 hours.

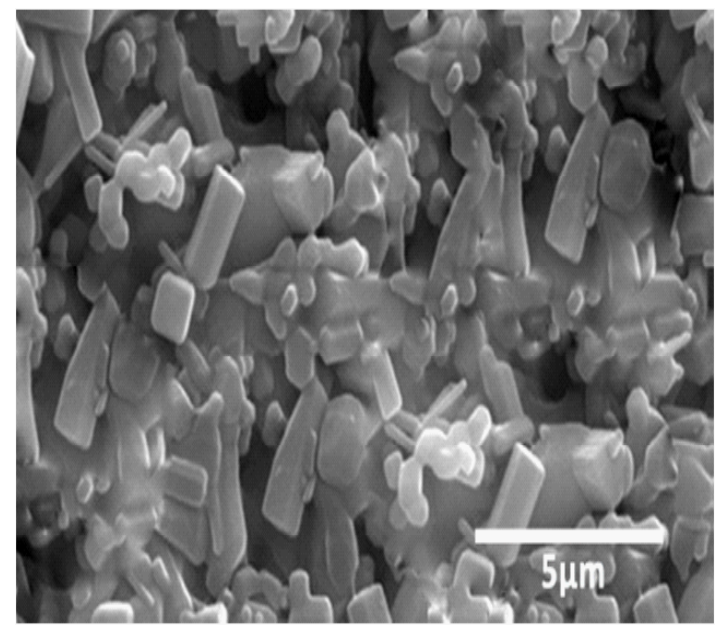

Fig. 2: SEM analyses of ZnS nanoparticles using leaf extract Tridaxprocumbens 


\section{RESULT AND DISCUSSIONS}

\section{XRD Pattern}

The crystalline structural properties of prepared biosynthesis of ZnS nanoparticles powder sample is studied using $X$-ray diffraction figure 1 shows the different peak pattern of synthesized ZnS at $2 \theta$ value of $31.82^{\circ}, 34.63^{\circ}, 36.07^{\circ}, 48.72^{\circ}, 54.04^{\circ}$ and $63.05^{\circ}$ and corresponding reflection planes is $100,002,101,102,110$ and 103 respectively it indicate Hexagonal Wurtzite structure.

Debye Scherrer's equations were used to calculate particle crystalline grain size of the $\mathrm{ZnS}$.

$\mathrm{D}=\frac{\mathrm{K} \lambda}{\beta \operatorname{Cos} \theta} \AA$

Here $\mathrm{D}$ is the mean of grain size, $\mathrm{K}=$ 0.9 constant value, $\lambda=0.5323 \AA$ is $x$-ray wavelength for CuKa radiation, $\theta$ is the diffraction angle in radian, $\beta$ is full with half maximum (FWHM) in radian so the average grain size of synthesis zinc sulphide is $\sim 40 \mathrm{~nm}$

\section{Morphology studies}

Figure 2 clearly shows the surface morphology of biosynthesized zinc sulphide nanoparticle powder were examined and found different radial hexagonal, spherical, rod shapes and some surface areas various size of hexagonal shape particles observed and their size was found to be less than $5 \mu \mathrm{m}$.

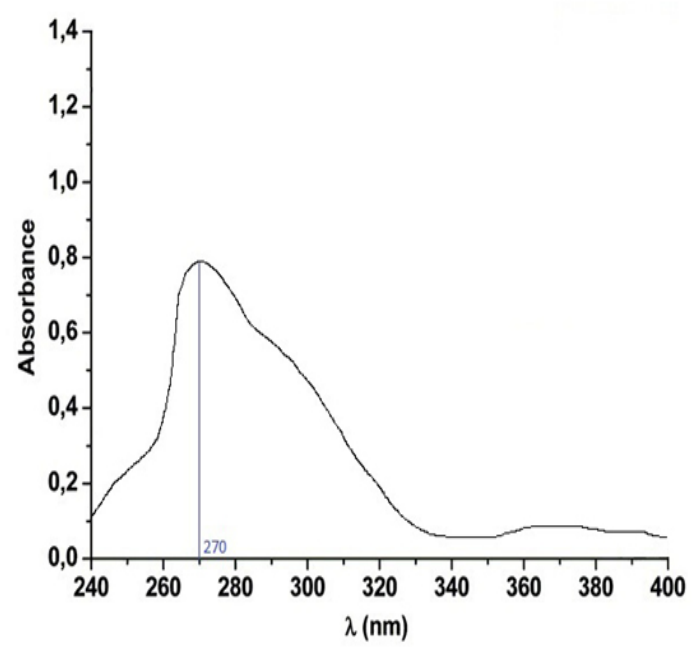

Fig. 3: UV-Visible analysis of ZnS nanoparticles using leaf extract tridaxprocubens

\section{UV- Visible analysis}

The optical absorption of biosynthesized zinc sulphide nanoparticle clearly shown in figure 3 and absorption range $200-400 \mathrm{~nm}$, the maximum absorption occurred at $270 \mathrm{~nm}$.

\section{FT-IR Spectrum}

The FTIR analysis of zinc sulpide nanoparticles synthesized using tridaxprcumbens methanol leaf extract showed in figure 4, ranging from $500-4000 \mathrm{~cm}^{-1}$ wave numbers and its produces zero to two N-H absorptions depending on its type at $3850.50 \mathrm{~cm}^{-1}$, Alkenyl C-H stretch at $3101.94 \mathrm{~cm}^{-1}$, Alkenyl $\mathrm{C}=\mathrm{C}$ stretch at $1642.05 \mathrm{~cm}^{-1}$, Aromatic $\mathrm{C}=\mathrm{C}$ Bending at $1502.47 \mathrm{~cm}^{-1}$, Polysaccharides at 1091.33 $\mathrm{cm}^{-1}$ and C-H Vibration at $594.62 \mathrm{~cm}^{-1}$ according to this stretching $\mathrm{ZnS}$ nanoparticles have degradation of TGA

\section{Antimicrobial activity of $\mathrm{ZnS}$}

Muller Hinton Agar (MHA) plate from Himedia Mumbai very useful to screening antimicrobial activity, Here disc diffusion method was helpful to analysis antimicrobial activity. Before swap inoculums in the MHA plate surface it was treated $15 \mathrm{ml}$ molten media in to sterile petriplates from pouring process and allowed 5 minutes for solidify then the minimum amount of $(0.1 \%)$ microorganisms suspension was transferred uniformly in MHA plate surface and allowed 5 minute for drying , then $60 \mathrm{mg}$ concentration disc placed on $6 \mathrm{~mm}$ sterile disc that

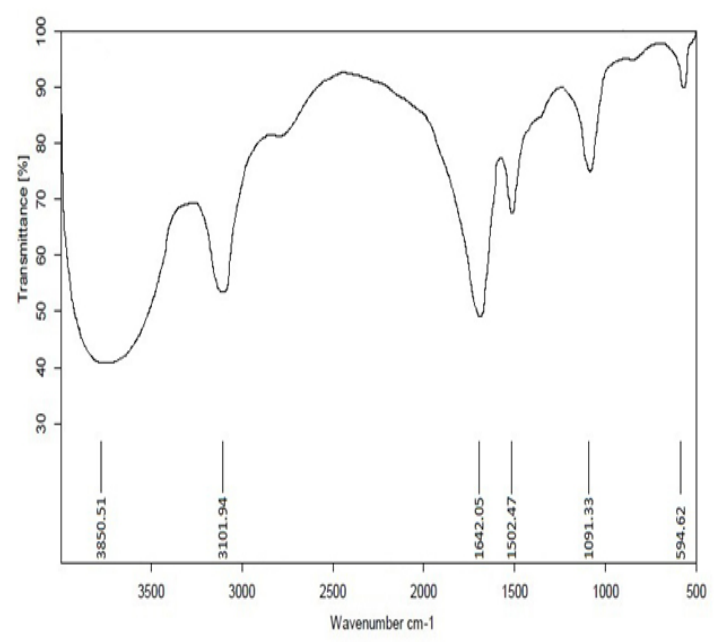

Fig. 4: FTIR analysis of ZnS nanoparticles using leaf extract Tridaxprocumbens 
was palced in surface of MHA plates for allowing 5 minutes to diffuse the ZnS leaf extract solution, after diffused that MHA plates are placed incubation at $37^{\circ} \mathrm{C}$ for 24 hours, during the incubation zone of inhibition formed around the sterile disc and zone was calculate by using transparent millimeter ruler.The phytochemical analysis of methanol leaf extract of tridaxprocumbens zinc sulphide was clearly indicate the Table 1 and the plant found a Ikaloids, flavonoids, phenol,crbohydrates,steroids were absent in Terpenoid,anthrouinone,saponins

Table 1: Qualitative phytochemical analysis of $\mathrm{ZnS}$ nanoparticles using leaf extract of Tridaxprocumbens

\begin{tabular}{|c|c|c|}
\hline $\begin{array}{l}\text { Phyto } \\
\text { chemicals }\end{array}$ & Observations & $\begin{array}{l}\text { Extracts } \\
\text { Methanol }\end{array}$ \\
\hline Alkaloids & & + \\
\hline Mayer's test & Cream color & + \\
\hline Wagner's test & $\begin{array}{l}\text { Reddish brown } \\
\text { solution/ precipitate }\end{array}$ & \\
\hline Flavonoids & & + \\
\hline $\begin{array}{l}\text { Lead acetate test } \\
\mathrm{H}_{2} \mathrm{SO}_{4} \text { test }\end{array}$ & $\begin{array}{l}\text { Yellow orange } \\
\text { Reddish brown / } \\
\text { Orange color } \\
\text { precipitate }\end{array}$ & + \\
\hline Steroids & & + \\
\hline Liebermann- & $\begin{array}{l}\text { Violet to blue } \\
\text { or Green }\end{array}$ & \\
\hline Burchard test & color formation & \\
\hline Terpenoids & & - \\
\hline Salkowski test & $\begin{array}{l}\text { Reddish brown } \\
\text { precipitate }\end{array}$ & \\
\hline Arthroquinone & & - \\
\hline Borntrager's test & Pink color & \\
\hline Phenols & & + \\
\hline $\begin{array}{l}\text { Ferric chloride test } \\
\text { Lead acetate test }\end{array}$ & $\begin{array}{l}\text { Deep blue to Black } \\
\text { color formation } \\
\text { White precipitate }\end{array}$ & + \\
\hline Saponin & Stable persistent & - \\
\hline Tanin & $\begin{array}{l}\text { Brownish green } \\
\text { / Blue black }\end{array}$ & - \\
\hline Carbohydrates & $\begin{array}{l}\text { Yellow / brownish / } \\
\text { blue / green color }\end{array}$ & + \\
\hline Oils \& Resins & Filter paper method & - \\
\hline
\end{tabular}

'+' Present, '-'Absent ,tannins oil and resins. In this different functional which was helpful to react with zinc sulphide and increase a zone of inhibitions, FTIR analysis shows different function group bonding to enter the cell membrane of inoculums. The quantitative analysis by presence and absence of inhibition zone, methanol leaf extract of zinc sulphide using tridaxprocumbns has excellent antimicrobial activity against all tested microorganisms its clearly shown in figure 5 . It was tested both gram positive, gram negative bacteria's and fungal culture by disc diffusion method the zone of inhibition is formed antibiotic action of zinc sulphide nanoparticles. Table 2 clearly indicate antimicrobial activity of all tested microorganism with different concentration at $30 \mu \mathrm{l}, 40 \mu \mathrm{l}, 50 \mu \mathrm{l}$ and $60 \mu \mathrm{l}$, in this six microorganisms Staphylococcus aureus, Bacillus subtilis are gram positive and Escherichia coli, Pseudomonas aeruginosa are gram negative and Candida albicans, Aspergillusniger is fungus culture, at a concentration $30 \mu \mathrm{l}$ P.aeruginosa start a high zone of inhibition ( $15 \mathrm{~mm}$ ) followed by S.aureus and E.coli(14 mm), minimum zone of inhibition was found in B.subtilis $(8 \mathrm{~mm}$ ) from bacterial culture but in a fungus culture C.albicans $(11 \mathrm{~mm})$ and A.niger $(10 \mathrm{~mm})$ here C.albicans lead high zone of inhibition to compare A.niger.

The concentration $40 \mu \mathrm{l}$ and $50 \mu \mathrm{l}$ same zone of inhibition was increased in both bacterial and fungal culture but concentration $50 \mu \mathrm{l}$ B.subtils inhibition zone was increased as the same of A.niger fungus culture, S,aureus inhibition zone also increased to compare E.coli, but the maximum zone was found in P.aeruginosa at $40 \mu \mathrm{l}$ and $50 \mu \mathrm{l}$ concentration.

Table 2: Antimicrobial activity of ZnS nanoparticles using leaf extract of Tridaxprocumbens

\begin{tabular}{lccccc}
\hline Organism & \multicolumn{5}{c}{$\begin{array}{c}\text { Different concentration } \\
\text { of ZnS samples }\end{array}$} \\
\cline { 2 - 6 } & $\mathbf{C}$ & $\mathbf{3 0} \boldsymbol{\mu l}$ & $\mathbf{4 0} \boldsymbol{\mu l}$ & $\mathbf{5 0} \boldsymbol{\mu l}$ & $\mathbf{6 0} \boldsymbol{\mu l}$ \\
\hline S.aureus & 26 & 14 & 15 & 18 & 20 \\
B.subtilis & 25 & 8 & 10 & 13 & 18 \\
E.coli & 24 & 14 & 16 & 17 & 20 \\
P.aerugoinosa & 28 & 15 & 16 & 19 & 22 \\
C.albicans & 24 & 11 & 14 & 18 & 20 \\
A.niger & 25 & 10 & 11 & 13 & 15 \\
\hline
\end{tabular}




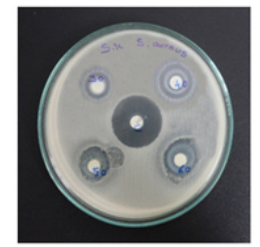

A) Staphylococcus aureus (gram-positive)

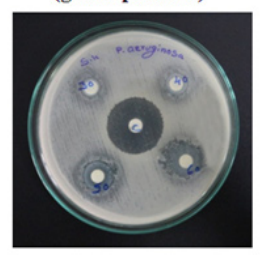

(D) Pseudomonas aeruginosa (gram-negative)

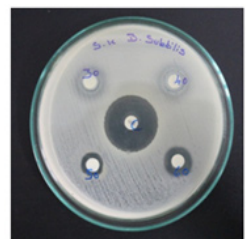

(B) Bacillus subtilis (gram-positive)

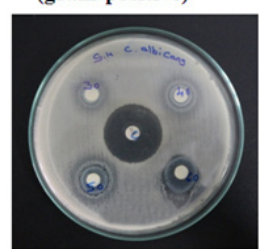

(E) Candida albicans (Fungus)

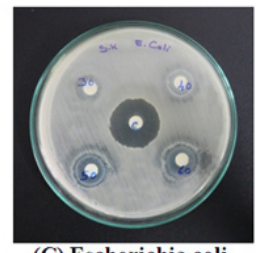

(C) Escherichia coli (gram-negative)

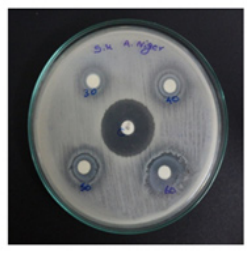

(F) Aspergillus niger (Fungus)

Fig. 5: Antimicrobial activity of $\mathrm{ZnS}$ nanoparticles using leaf extract of Tridaxprocumbens

Finally the maximum zone of inhibition were observed at $60 \mu \mathrm{l}$ concentration for P.aeruginosa (22 $\mathrm{mm})$ and minimum zone of inhibition was observed B.subtilis $(18 \mathrm{~mm})$ and A.niger $(15 \mathrm{~mm})$, so the in vitro antimicrobial activity of biosynthesized zinc sulphide leaf extract was high excellent activity against all tested microcrganisms, the tridaxprocumbens various plant parts are used to found antimicrobial agents ${ }^{33}$ there are so many plants are have high antimicrobial activity because of their zone of inhibition against bacteria and fungus ${ }^{34}$ Biosynthesis is good and new field of research because it's from natural sources ${ }^{35}$.

\section{CONCLUSION}

In conclusion, we have reported a biosynthesized of zinc suphide nanoparticles using methanol leaf extract tridaxprocumbens for the first time, and the structural characterization and morphology of the zinc sulphide nanoparticles analyzed using XRD and SEM, the ZnS nanoparticles are Hexagonal wurtzite structure and average grain size of the nanoparticles is $40 \mathrm{~nm}$ and surface morphology was found various size of nanoparticles blow $5 \mu \mathrm{m}$, the optical observation of the colloidal solution were studied using UV-Visible the maximum absorption frequency was $270 \mathrm{~nm}$ and FTIR very useful to found different functional group present in the leaf extract solution. Further antimicrobial activity of tridaxprocumbens methanol leaf extract and synthesized zinc sulphide nanoparticles were investigated in the disc diffusion method from the result it's clear to known that the zinc sulphide nanoparticles have excellent zone of inhibition in the all tested pathogenic microcoranisms like Staphylococcus aureus, Bacillus subtilis are gram positive and Escherichia coli, Pseudomonas aeruginosa are gram negative and Candida albicans, Aspergillusniger is fungus culture. The maximum zone of inhibition was observed in Pseudomonas aeruginosa $(22 \mathrm{~mm})$ in $60 \mu \mathrm{l}$ concentration and minimum was observed in Aspergillusniger(15 $\mathrm{mm}$ ), it was evident that the methanol leaf extract tridaxprocumbens can be used to synthesis $\mathrm{ZnS}$ nanoparticles using green chemistry method for various applications.

\section{REFERENCE}

1. Manojkumar, K.; Sivaramakrishna, A.; Vijayakrishna, K. JNanopartRe.2016, 18,103

2. Chang, CC.; Chiang, FC.;Chen, SM.;
Thangavelu, K; Yang, HJ Int. J. Electrochem. Sci.2015, 11 (3), 2142-2152

3. Palanisamy, S.; Thangavelu, K.; Chen, S.M. ; Thirumalraj, B.; Liu, X.H.Sens. Actuators, 
B.2016, 233, 298-306.

4. Palanisamy, S. ; Thangavelu, K.; Chen, S.M.; Velusamy, V.; Chen, TE.; Kannan, RSJ. Electroanal. Chem.2017, 785, 40-47.

5. Thangavelu, K.; Palanisamy, S.; Chen, S.M.; Velusamy, V.; Chen, T.W. ; Kannan, R.S. J. Electrochem. Soc.2016, 163(14,726-731.

6. Palanisamy, S.; Thangavelu, K.; Chen, S.M.; Gnanaprakasam, P.; Velusamy, V.; Liu, X.H.carbohydr. Polym.2016, 151, 401-407.

7. Thirumalraj, B.; Palanisamy, S.; Chen, S.M.; Thangavelu, K.; Periakaruppan, P.; Liu, X.H.J. Colloid Interface Sci. 2016, 475, 154-160.

8. Palanisamy, S.; Thangavelu, K.; Chen, S.M.; Velusamy, V.; Chang, M.H.; Chen, T.W.; AlHemaid, F.M.A.; Ali, M.A.; Kannan, R.S.Sens. Actuators, B. 2017, 243, 888894.

9. Ameer, A.; Faheem, A.; Nishat, A.; Chaman, M.; Naqvi, A.H. Jou. Alloy. Com.2010, 496, 399-402.

10. Alessio, B.; Maximilian, D.; Pierandrea, L., Nostro. PB. Journal of Nanopart Res.2007, 10, 679-689.

11. Surabhi, S.; Putcha, V.; Vankarango, R.; and Gollapallinageswsara. R. International nano letters. 2013, 3, 30.

12. Grasseta, F.; Saitoa. N.; Lia, D.; Parka, D.; Sakaguchia, I.; Ohashia, N.; Hanedaa, H.; Roisnelc, T.; Mornet, S.; Duguet, E. Jou. Alloys. Com. 2003, 360 , 298-311.

13. Deepti, K.; Pradeep, T. Jou. Crystal growth.2009, 311-3889.

14. Li, M.; Bala, H.; Lv, X. Jou. Mate. Lett.2007, 61-690.

15. Xiaoxia, Lin.; FeiRong.;Degang, Fu.; Chunwei, Yuan. Jou. Powder Tech.2012, 219, 173178.

16. Pieqiang,Li.; Guohua, Zhao. Jou. Dye and pigments.2012,92, 923-928.

17. Ravindra, P.; Singh, V.K.; Shukla.; Raghvendra, S.; Yadav, P.K.; Sharma, P.K.; Avinash, C.P. Jou. Advanced Materials Letters. 2011,. 2,.4, 313-317.

18. Harish, K. H.; PrashanthKumar, J.; Shruthi, SD. Spreng. Pharmacophore.2010, 13, 231238.

19. Akl, M.; Awwad, N.M.; Amany. O. Jou.
Nanoscience and Nanotechnology.2012, 2012, 2(6), 164-170.

20. Sigh. R. P.; Magesh. S.; Rakkiyappan. C. Jou. Nanotechnology and application. 2012, 6, 43- 51.

21. Ingale.G.; Chaudhari, A.N. Jou. Nanomedicine and Nanotechnology. 2013, 4, 1-7.

22. Sahoo. M.; Chand. P.K. Jou. Phytomorphology. 1998, 48, 195 - 206.

23. Ali. M.; Ravinder. E.; Ramachandram. R. Jou. Fitoterapia.2001, 72, 313-315.

24. Ravikumar. V.; Shivashangari. K.S.; Devaki.T. Jou. Mol. Cell Biochem. 2005, 269, (1-6).

25. Vyas . P. S.; Tiwari . U.; Rastogi. B.; Singh. P.; Journal of Ethnopharmacologoly. 2004, 92, 113-119.

26. Bhagwat. D.A.; Killedar, Suresh. G.; Adnaik. R.S. International Journal of Green Pharmacy. 2010, 2(2), 126-128.

27. Deepali. S; Sapna. S.; Kaitha. B. S.; Jaspreet. R.; Mohinder. K.; Applied Surface Science. 2011, 257, 9661-72.

28. Bibitha. B.; Jisha. V.K.; Salitha. C.V.; Mohan. S. Journal of Current Agriculture. 2002, 28, 75-78.

29. Maghrani. M.; Zeggwah. N.; Michel. J.; Eddouks. M. Jou. Ethnopharm.2005, 102(1-2), 193-197.

30. Ravindra.S. Physicochemical and Engineering Aspects2010, 367.1, 31-40.

31. Padmavati. N.V.; Vijayaraghavan. R. Sci. Technol.Adv.Mater. 2008, 9, 1468.

32. Meena.W.; Shubha. Jain. Jou.Mat,Sci.2015, 04, 36-39.

33. Vanaja. M.; Rajeshkumar. S.; Paulkumar. K.; Gnanajobitha. G.; Malarkodi. C.; Annadurai. G. International Journal of Materialsand Biomaterials Application. 2013,3(1), 1-4.

34. Malarkodi. C.; Annadurai. G. Jou. Applied Nanoscience. 2013,3(5), 389-395.

35. Warad. H. C.; Ghosh. S. C.; Hemtanon. B.; Thanachayanont. C.D. Jou. Sci.Technol.AdV. Mater. 2005, 6, 296.

36. Baishya. U.; Sarkar. D. Indian Jou. ofpure\& Applied Physics. 2011, 49, 186-189.

37. Thakkar. K.N.; Mhatre.S.S.; Parikh. R.Y. Jou. Nanomed.2010, 6, 257-262.

38. Sheng. Xu.;Zhong. L.W. Jou.Nanoresearch. 2011,4(11), 1013-1098. 